\title{
PERCEPÇÕES \\ E REFLEXÕES \\ DOS PROFESSORES \\ SOBRE AS PRÁTICAS \\ PEDAGÓGICAS DE \\ TRANSLINGUAGEM \\ NO ENSINO BILÍNGUE \\ EM MOÇAMBIQUE
}

\author{
PERCEPCIONES Y REFLEXIONES DE LOS PROFESORES SOBRE LAS PRÁCTICAS \\ PEDAGÓGICAS DE TRANSLENGUAJE EN LA ENSEÑANZA BILINGÜE EN MOZAMBIQUE
}

TEACHER'S PERCEPTIONS AND REFLECTIONS ON TRANSLANGUAGING PEDAGOGICAL PRACTICES IN BILINGUAL EDUCATION IN MOZAMBIQUE

Gervásio Absolone Chambo*

Universidade Eduardo Mondlane| Moçambique

\begin{abstract}
RESUMO: Este estudo tem como objetivo discutir as percepções e reflexões dos professores de ensino bilíngue em Moçambique sobre a exploração das práticas de translinguagem nas classes de pós-transição. Com base na análise de entrevistas não-estruturadas e das sessões de discussão em grupo no processo de validação interna e externa dos resultados, este estudo constatou que os professores reconhecem os problemas pedagógicos associados ao uso da pedagogia monoglóssica nas classes de pós-transição. No entanto, os professores que participaram nas experiências práticas de translinguagem são favoráveis ao uso desta nas classes de póstransição ao passo que os professores que exclusivamente analisaram as evidências de translinguagem na sala de aulas defendiam a perspectiva monoglóssica nas práticas de translinguagem. O estudo conclui que os professores analisam a relevância das práticas de translinguagem nas classes de pós-transição a partir de visões da pedagogia monoglóssica e das evidências de aprendizagem qualitativa da L2 e dos conteúdos académicos.
\end{abstract}

PALAVRAS-CHAVE: Translinguagem. Ensino bilíngue. Professores. Pedagogia monoglóssica/ heteroglóssica. Moçambique.

* Doutor em Estudos Linguístico pela Universidade de Vigo. Professor na Universidade Eduardo Mondlane. E-mail gervasio.chambo@uem.mz. 
RESUMEN: Este estudio tiene como objetivo discutir las percepciones y reflexiones de los profesores de enseñanza bilíngue en Mozambique sobre la explotación de las prácticas de translenguaje en las clases de postransición. Con base en el análisis de entrevistas no estructuradas y de las sesiones de discusión en grupo en el proceso de validación interna y externa de los resultados, este estudio constató que los profesores reconocen los problemas pedagógicos asociados al uso de la pedagogía monoglósica en las clases de postransición. Sin embargo, los profesores que participaron en las experiencias prácticas de translenguaje son favorables al uso de esta en las clases de postransición, mientras que los profesores que exclusivamente analizaron las evidencias de translenguaje en el aula defendían la perspectiva monoglósica en las prácticas de translenguaje. El estudio concluye que los profesores analizan la relevancia de las prácticas de translenguaje en las clases de postransición a partir de la perspectiva de pedagogía monoglósica y de las evidencias de aprendizaje cualitativo de la L2 y de los contenidos académicos.

PALABRAS CLAVE: Translenguaje. Enseñanza bilíngue. Profesores. Pedagogía monoglóssica/ transglósica. Mozambique.

ABSTRACT: This study aims to discuss the perceptions and reflections of bilingual education teachers in Mozambique on the exploration of translingual practices in post-transition grades. Basing on the analysis of unstructured interviews and the group discussion sessions in the process of internal and external validation of the results, this study found that teachers recognize the pedagogical problems associated with the use of monoglossic pedagogy in post-transition grades. However, teachers who participated in the translingual practice experiences favoured the use of translanguaging in post-transition grades whereas teachers who exclusively analysed the evidence of translanguaging in the classroom advocated the monoglossic pedagogical perspective in translingual practices. The study concludes that the teachers' reflections about using of translanguaging pedagogical practices in post-transition grades are based on monoglossic pedagogy perspective and the evidence of qualitative learning of L2 and academic contents.

KEYWORDS: Translanguaging. Bilingual education. Teachers. Monoglossic/ heteroglossic pedagogy. Mozambique.

\section{INTRODUÇÃO}

Nos contextos africanos cujas políticas linguísticas e educacionais são exoglóssicas, desenvolvem-se programas transicionais em que a L1 é meio de instrução nas primeiras duas ou três classes e a posterior ocorre a transição para L2 (Inglês, Francês e Português) que se torna o principal meio de instrução (HEUGH, 2011). As L1 são limitadas à literacia nas classes iniciais ao passo que as L2 são usadas para o ensino da ciência (MAZRUI, 2002). As orientações pedagógicas do programa transicional adotado em Moçambique em 2003 e revisto em 2019 (Estratégia de Expansão do Ensino Bilíngue 2020-2029 (MINEDH, 2019)) advogam o princípio de separação e/ou de fronteiras de línguas nas classes de pós-transição onde a L2 (português) é o principal meio de instrução e L1 (língua moçambicana) é explorada como meio auxiliar da L2 (INDE/MINED, 2003; MINEDH, 2019). O princípio de separação e/ou fronteiras de línguas é uma estratégia pedagógica da perspectiva monoglóssica que, em realidade obriga aos professores a perpetuar a exposição máxima à L2 e evitamento da L1 nas classes de pós-transição. A título de exemplo, as orientações pedagógicas para as classes de pós-transição preveem que os professores recorram ao método prever-rever nas aulas. Em termos práticos, este método determina o uso de cada língua em momentos específicos de aula, isto é, sem "misturar" as línguas (INDE/MINED, 2003). No entanto, os alunos não possuem a proficiência linguística e acadêmica desenvolvida em L2 ao ponto de aprenderem sem a liberalização da L1 e da L2 nas aulas e, mais ainda, os conteúdos são cognitiva e academicamente exigentes (CHAMBO, 2020). Os professores do ensino bilíngue reconhecem as limitações linguísticas e pedagógicas associadas ao ensino numa perspectiva monoglóssica nas classes de pós-transição (CHAMBO, 2016) mas, a sua falta de consciência em relação aos papéis comunicativos, pedagógicos e sociais da L1 nas situações de ensino de/em L2 suscita posicionamentos divergentes em relação ao uso ou não de duas ou mais línguas nas aulas (CHIMBUTANE, 2015).

García (2009), García e Wei (2014) e Flores e Beardsmore (2015) entendem que os programas de ensino bilíngue assumem e promovem o monolinguismo como norma no ensino através de práticas pedagógicas alicerçadas na perspectiva monoglóssica e na convicção de que o uso flexível de ambas línguas na sala de aulas ameaça a aprendizagem de/em L2 (JACOBSON, 1990; COOK, 2001; CUMMINS, 2007). Contudo, esta perspectiva monoglóssica é desafiada por novas práticas pedagógicas alicerçadas na perspectiva heteroglóssica e/ou transglóssica da qual se destaca a translinguagem (BAKER, 2001; GARCÍA, 2009; 
CANAGARAJAH, 2011), que é uma estratégia pedagógica e metadiscursiva que propõe a liberalização das práticas linguísticas bi/multilíngues como um único repertório linguístico nos contextos multilíngues (GARCÍA, 2009; CREESE; BLACKLEDGE, 2010; GARCÍA; WEI, 2014).

Este estudo parte das experiências pedagógicas dos professores baseadas na perspectiva monoglóssica em L2 no ensino bilíngue e analisa as suas reflexões e os seus posicionamentos em relação às práticas de translinguagem exploradas nas classes de pós-transição. As práticas de translinguagem liberalizaram o uso de ambas línguas como um único repertório linguístico, discursivo e didático no ensino-aprendizagem de ciências naturais, contrariamente à pedagógica de separação, fronteira e maximização da L2 e evitamento da L1 instituída para as classes de pós-transição (INDE/MINED, 2003). Duas perguntas de estudo são formuladas a respeito deste tema, nomeadamente: (i) Como os professores de ensino bilíngue com experiência confirmada no ensino baseado na pedagogia monoglóssica avaliam as práticas pedagógicas da translinguagem nas classes de pós-transição? (ii) Que significados os professores constroem sobre as práticas de translinguagem num contexto em que o ensino bilíngue visa promover o desenvolvimento de proficiência dos alunos em L2 nas classes de pós-transição?

\section{TRANSLINGUAGEM NA SALA DE AULAS E AS CRENÇAS E/OU PERCEPÇÕES DOS PROFESSORES}

Ainda que vários estudos sobre a translinguagem sejam massivamente publicados em livros e revistas científicas, poucos têm-se debruçado sobre a translinguagem e as percepções dos professores no contexto africano.

O estudo de Mwanza (2017), realizado nas escolas rurais da Zâmbia, um país multilíngue em que o inglês é uma L2 aprendida no ambiente escolar, mostra como os professores de inglês repudiam o uso das L1 dos alunos através de práticas de translinguagem. A tese dos professores é sustentada pelas ideologias monolíngues segundo as quais a língua-alvo tem de ser ensinada na própria línguaalvo e que a integração da L1 ocasionaria a interferência (MWANZA, 2017). Entretanto, Mashinja e Mwanza (2020) estudaram as práticas pedagógicas heteroglóssicas dos professores primários namibianos. As práticas de translinguagem desafiam a pedagogia monoglóssica instituída pelo currículo à medida que exploram as línguas dos alunos no ensino, criando oportunidades de construção de significados nas aulas, maximizando a participação dos alunos bem como facilitando os processos de aprendizagem. Nyimbili e Mwanza (2021) constataram que os professores consideram as práticas pedagógicas de translinguagem mais onerosas em termos de tempo de aula e desajustadas à avaliação que é feita na língua de instrução (cinyanja, L2). Por estas razões, os autores concluíram que os professores advogam que o letramento inicial seja desenvolvido exclusivamente em L1 dos alunos.

Em Moçambique, Chimbutane (2015) estudou as práticas dos professores de ensino bilíngue no ensino de Português. O desconhecimento que os professores de ensino bilíngue apresentam em relação ao ensino de Português como L2 confunde e/ou diverge os seus posicionamentos em relação ao uso ou não da L1 como meio auxiliar no ensino de Português nas classes de póstransição. Enquanto alguns professores preferem excluir o uso da L1, em conformidade com a pedagogia de separação de línguas, outros veem-na como um meio imprescindível para o ensino de Português através de alternância de códigos (CHIMBUTANE, 2015). Ainda no contexto moçambicano, Terra (2018) constatou episódios de translinguagem e de alternância de códigos nas classes iniciais em que os professores preferiam o ensino em português, L2, como meio de instrução - ao invés da L1 prescrita no currículo. Este fato é justificado pela falta de formação pedagógica dos professores sobre o ensino bilíngue (uso da L1 como meio de instrução), não domínio da L1 dos alunos pelos professores e não inexistência de materiais didáticos.

Omidire e Ayob (2020) analisaram os prós e contras que se circunscrevem ao uso de translinguagem (inclusão das L1 no ensino em inglês) no ensino primário sul-africano. Os alunos e os professores apresentaram atitudes positivas em relação à translinguagem como estratégia de ensino, contudo, a complexidade das línguas, as visões contraditórias em relação à L1, a insuficiência de recursos e de materiais de ensino nas escolas e a falta de formação pedagógica dos professores para ensinar em contextos de sala de aulas multilíngues são os principais que desfavorecem o uso da translinguagem nas escolas sul-africanas. Probyn (2019) estudou o ensinoaprendizagem da ciência em oito escolas rurais e suburbanas sul-africanas cujos professores ensinavam usando a pedagogia monolíngue (separação de línguas) (professores B’) e os outros, explorando a pedagogia heteroglóssica orientada para o multilinguismo e para a pedagogia translinguagem (professores B). Probyn (2019) concluiu que as práticas dos professores B criam 
maiores oportunidades para os alunos aprenderem a ciência do que as práticas monolingues dos professores B’. As práticas da pedagogia de translinguagem são suficientemente condicionadas pela coerência entre o conteúdo da aula e os níveis de engajamento dialógico e discursivo dos alunos na construção dos significados do conhecimento científico.

Makalela (2015) analisou as percepções dos professores em formação inicial sobre a inclusão das diferentes línguas sul-africanas nas aulas de sepedi, uma das 11 línguas oficiais do país. Os resultados do estudo indicavam que a translinguagem facilitava a aprendizagem, expandia os repertórios linguísticos, permitia a intercompreensão mútua dos alunos de diferentes línguas, rompendo as barreiras e os enclaves linguísticos impostos pelo monolinguismo e pela separação entre as línguas no regime de apartheid. Neste sentido, o autor classificou a translinguagem como uma das formas de manifestação de filosofia ubuntu segundo a qual "uma língua é incompleta sem a outra”, ou seja, há uma interdependência entre a visão de mundo africana e o uso das línguas sem fronteiras e que se constroem e se reafirmam as identidades multilíngues e multiculturais através da promoção de espaços multilíngues nas aulas (MAKALELA, 2015).

Charamba (2020), num estudo sobre as práticas de translinguagem no ensino de ciências desenvolvidas pelos professores no Zimbabwe, cujos alunos apresentavam baixos níveis de proficiência linguística e acadêmica em inglês, L2, concluiu que os professores reconhecem que as práticas de translinguagem tornam a ciência mais compreensível contrariamente ao ensino exclusivamente monolíngue em L2.

Fora do contexto africano, Barros et al., (2020) exploraram as crenças e as percepções dos professores norte-americanos em formação inicial em relação ao multilinguismo, ensino de línguas e à translinguagem. As conclusões do estudo revelam que os professores possuem crenças baseadas na perspectiva monolingue e na inexperiência prática no uso da translinguagem em contextos de salas de aulas multilíngues tal que a consideram não funcional para o ensino de línguas senão no ensino bilíngue (BARROS et al., 2020). Grenner e Jönsson (2020) mostram que os professores suecos valorizam o uso exclusivo do inglês sem a integração da L1 dos alunos nas aulas. Entretanto, concordam que a translinguagem possa ser usada nas aulas de inglês de forma apropriada desde que se garanta a paridade de proficiência linguística nos alunos.

Yuvayapan (2019) mostra que alguns professores de inglês, L2 na Turquia consideram a translinguagem como "scaffolding ${ }^{1 "}$, uma perspectiva pedagógica oportuna nos momentos pontuais na aula. Entretanto, a perspectiva monolingue de ensino de inglês defendida pelas instituições e por outros professores de inglês coagem a reprová-la como uma pedagogia não sistemática e nãofuncional para o ensino ainda que as suas práticas provem o contrário.

Menken e Sánchez (2019) denunciam que a translinguagem quebra a ideologia monolíngue das escolas e dos professores no contexto norte-americano. Os professores norte-americanos reconhecem o valor pedagógico desta perspectiva no ensino, adotamna nas suas práticas pedagógicas diante dos alunos bilíngues emergentes ao invés das práticas ideológicas e pedagógicas monolingues em inglês. Por seu turno, os professores do estudo de Deroo e Ponzio (2019) concluíram que a translinguagem é, no contexto norte-americano, uma perspectiva linguística e pedagógica adequada para o desenvolvimento dos alunos bilíngues e ao mesmo tempo um recurso vital para o ensino-aprendizagem uma vez que rompe a perpetuação das práticas de ensino e avaliação monolingues nas salas de aulas multilíngues.

Holdway e Hitchcock (2018) analisaram as ideologias pedagógicas dos professores de Hawai, nos Estados Unidos de América, em relação à introdução de práticas translíngues (uso das diferentes L1 dos alunos) no ensino de matemática em contextos de sala de aulas multilíngues com base na pedagogia monolingue. Os professores repudiaram as práticas monolíngues ao constatarem que as práticas translíngues transformavam e adequavam-se ao ensino nas turmas multilíngues à medida que as diferentes línguas eram

\footnotetext{
${ }^{1}$ Segundo Gibbons (2015, p.16), "scaffolding” nada mais é para além da ajuda (andaime) que os professores prestam temporariamente aos alunos para que mais tarde aprendam novas habilidades, conceitos ou níveis de sozinhos.
} 
usadas como recursos nas aulas de matemática. Entretanto, o sucesso da sua implementação tem de ser negociado entre a experiência anterior dos professores, as práticas e as exigências linguísticas dos alunos na sala de aulas (TICHELOVEN et al., 2019).

Wang (2019) constatou atitudes favoráveis dos professores chineses de mandarim e dos respectivos alunos de diferentes línguas apresentam em relação às práticas de translinguagem. Ambos as consideram como estratégias de "scaffolding", porque as diferentes línguas dos alunos são liberalizadas e usadas para fins de negociação de significados e de conhecimento através de uma comunicação amistosa professor-aluno. Na Nova Papua Guiné, os professores de inglês língua estrangeira consideram que as práticas de translinguagem assumem vários significados em termos pedagógicos desde a facilitação de uso e de interpretação dos materiais didáticos, comunicação segura e produtiva dos alunos, elevação da atmosfera de aprendizagem na sala de aulas, apoio dos alunos na língua-alvo, formulação das perguntas pelos alunos e desafio aos professores para a aprendizagem da língua local (SAHIB et al., 2020).

\section{CONCEPÇÃO METODOLÓGICA}

Este estudo parte de uma pesquisa-ação participactiva (STRINGER, 2007; MCNIFF; WHITEHEAD, 2010) desenvolvida com o objetivo de avaliar o impacto pedagógico da translinguagem e da aprendizagem transcultural como estratégias de ensino para as classes de pós-transição, visando revitalizar a participação discursiva dos alunos na sala de aulas. Com efeito, a metodologia concebida neste estudo tencionava colher dados nas aulas de ciências naturais, $4^{\text {a }}$ classe lecionadas com base na translinguagem e aprendizagem transcultural comparando com os dados das aulas lecionadas através da pedagogia monolingue em L2. Neste estudo são analisados parte dos dados relativos às práticas de translinguagem.

\subsection{LOCAL E PARTICIPANTES DO ESTUDO}

O estudo decorreu em quatro escolas primárias completas (EPC de Citimela, EPC de Wulombe, EPC de Ruwani e EPC de Mikhokhweni) selecionadas aleatoriamente e que ministram o ensino bilíngue nas zonas rurais da província de Inhambane. Estas escolas foram integradas em 2004 como pioneiras na fase da expansão do ensino bilíngue no país depois do sucesso da experiência desenvolvida pelo PEBIMO (1993-1997) nas províncias de Gaza e Tete. Deste estudo participaram 17 professores de ensino bilíngue; entre eles, há os que iniciaram em 2004 e os que se foram integrando ao longo dos anos subsequentes. Estes professores lecionavam em diferentes classes do ensino bilíngue. Em termos de capacitação para este ensino, os professores que iniciaram neste modelo de ensino em 2004 foram capacitados pelos técnicos do Instituto Nacional de Desenvolvimento da Educação (INDE). No entanto, os professores que se integraram nos anos subsequentes foram capacitados pelas Zonas de Influência Pedagógica (ZIP), pelos professores com experiência de capacitação e de lecionação no ensino bilíngue desde 2004. No entanto, alguns professores lecionavam no ensino bilíngue sem que tivessem participado em nenhuma capacitação. As capacitações versavam essencialmente sobre: currículo de ensino bilíngue; ortografia das L1 e alfabetização em L1. À medida que as classes se sucediam, os professores eram capacitados em matérias sobre uso de L1 nas classes de pós-transição, com enfoque para o método prever-rever e as orientações de separação de línguas e exposição máxima à L2 nas aulas. Nestas capacitações, os professores eram orientados a não explorar as práticas de pedagogias heteroglóssicas e/ou transglóssicas, tais como: tradução, alternância de códigos, exploração da L1 nas aulas de e/em L2.

\subsection{PROCESSO DE VALIDAÇÃO DOS RESULTADOS}

Por questões metodológicas, os resultados da pesquisa-ação participactiva são validados e/ou legitimados com base nos critérios e padrões de julgamento (MCNIFF; WHITEHEAD, 2010). Neste processo, constituíram-se dois grupos validação, a destacar:

(i) Grupo de validação interna (composto por professores internos à pesquisa provenientes da EPC de Ruwani e EPC de Citimela - que participaram nos ciclos de pesquisa-ação sobre as práticas de translinguagem e de aprendizagem transcultural); 
(ii) Grupo de validação externa (constituído por professores externos à pesquisa e provenientes das EPC de Wulombe e EPC de Mikhokhweni - que foram convidados para avaliar a viabilidade das práticas de translinguagem, analisando as evidências de aulas desenvolvidas nas escolas de ação inovadora em (i)).

Ambos grupos avaliaram os resultados do estudo usando os mesmos critérios e padrões de julgamento que foram definidos em cada ciclo da pesquisa-ação participactiva (STRINGER, 2007), nomeadamente: participação aberta, activa e voluntária dos alunos; nível de participação e de interação dos alunos e facilitação de ensino-aprendizagem. No entanto, o grupo de validação interna tinha experiências de participação nas práticas de planificação, observação, análise dos diferentes ciclos de pesquisa-ação diferentemente do grupo de validação externa.

\subsection{RECOLHA E ANÁLISE DE DADOS}

Os dados foram recolhidos a partir das entrevistas grupais não-estruturadas, de fichas de perguntas de validação dos resultados da pesquisa e de gravação áudio-visual (STRINGER, 2007; MCNIFF; WHITEHEAD, 2010). Para ambos grupos, concederam-se três aulas transcritas referentes à etapa inicial, intermediária e final dos ciclos de pesquisa-ação (totalizando: nove aulas diferentes), desenvolvidos nas EPC de Ruwani e EPC de Citimela (escolas de ação inovadora onde se realizaram as práticas pedagógicas de translinguagem e aprendizagem transcultural) e as respetivas aulas de controle provenientes da EPC de Mikhokhweni.

Os grupos de validação externa, além da avaliação das aulas transcritas analisadas individual e coletivamente em sessões de discussão dos grupos criados pelos professores de cada escola, assistiram aos respetivos vídeos, preencheram as fichas de perguntas de validação dos resultados da pesquisa que deviam preencher individualmente e depois participaram das sessões de entrevistas grupais não-estruturadas. Contrariamente, os grupos de validação interna, para além das aulas transcritas referentes às três etapas e das fichas de perguntas de validação dos resultados da pesquisa, participaram da entrevista grupal não-estruturada e recorreram às suas experiências práticas desenvolvidas ao longo dos diferentes ciclos de pesquisa-ação para validar os resultados da pesquisa.

A análise de dados usados neste estudo circunscreveu-se estritamente às reflexões e/ou posicionamentos dos professores nos grupos de validação interna e externa em relação à viabilidade da pedagógica da translinguagem no ensino de ciências naturais, nas classes de pós-transição a partir dos seguintes critérios e padrões de julgamento: participação aberta; ativa e voluntária dos alunos; nível de participação e de interação dos alunos e facilitação de ensino-aprendizagem e valores de evidências (MCNIFF; WHITEHEAD, 2010).

Com efeito, os dados gerados pelas entrevistas grupais não-estruturadas, fichas de perguntas de validação dos resultados da pesquisa, aulas transcritas e respetivos vídeos, foram transcritos e sistematizados de acordo com os critérios e padrões de julgamento definidos para a validação dos resultados da pesquisa (STRINGER, 2007). A seguir, efetuou-se a análise e interpretação dos dados (MCNIFF; WHITEHEAD, 2010), recorrendo à triangulação dos dados dos grupos de validação interna e os dos grupos de validação interna (JICK, 1979; MCNIFF; WHITEHEAD, 2010). O estudo foi desenvolvido respeitando os princípios da ética. Os sujeitos deste estudo participaram voluntariamente e sob termo de consentimento ético lido e assinado. O estudo recorreu aos pseudônimos fictícios com intuito de garantir a confidencialidade e proteger a identidade civil e física dos sujeitos, bem como das escolas envolvidas.

\section{RESULTADOS}

\subsection{EXPERIÊNCIAS PEDAGÓGICAS MONOGLÓSSICAS EM PORTUGUÊS, L2 NAS CLASSES DE PÓS-TRANSIÇÃO}

Os professores de ensino bilíngue têm experiências tanto do ensino em L1 antes da transição como do ensino em L2 nas classes de pós-transição que lhes permitem observar e refletir sobre a relação entre a língua de instrução e o impacto no ensino-aprendizagem. As reflexões e/ou posicionamentos dos professores ilustram por unanimidade que existem diferenças pedagógicas entre as classes lecionadas em L1 e as lecionadas em L2 (CHAMBO, 2016). Nas classes lecionadas em L2, os alunos encaram dificuldades para aprender em L2 proficientemente subdesenvolvida, ao passo que os professores enfrentam desafios para ensinar em L2 sem recorrer 
abertamente à L1 numa situação em que ambos são vítimas da transição precoce e da pedagogia monoglóssica. O extrato (1) retrata reflexões da professora Adhozani sobre as consequências pedagógicas do ensino-aprendizagem em L2 nas classes de pós-transição.

\section{Extrato 1: Prof. Adhozani (EPC de Mikhokhweni)}

[...] o que eu observo lá na minha sala a interação não é assim mesmo melhor. Ali os alunos não estão muito bem livres. Eu não sei se estão com medo ou o quê mas o que eu vejo é que não participam mesmo de uma forma desejada o que vinha acontecendo por exemplo nas aulas de citshwa lá na $3^{\text {a }}$ classe porque eles já estavam totalmente livres. Agora eu acho que eles agora sentem-se um pouco inibidos por questão da língua ou questão da assistência, não sei. [...]

A professora Adhozani expôs as diferenças entre as aulas em L2 ( $4^{\mathrm{a}}$ classe, pós-transição) e as aulas em L1 ( $1^{\mathrm{a}}$ à $3^{\mathrm{a}}$, antes da transição). Conforme se constata, os alunos mostram-se acanhados e tímidos, tal que não participavam interativamente nas aulas em L2 à semelhança das evidências das classes lecionadas em L1 (CHAMBO, 2020). Nesta reflexão, a professora Adhozani propôs, ainda que em dúvida, a possibilidade de conceder uma "assistência" que possivelmente podia ser uma abordagem pedagógica específica para as classes de pós-transição que tome em consideração o fato de que os alunos são bilíngues emergentes (GARCÍA, 2009) que não se acomodam às práticas pedagógicas monolíngues em L2 com evitamento da L1. Entretanto, o professor Milisi da EPC, de Wulombe (extrato 2, abaixo), partilhou em forma de denúncia, as atitudes dos alunos da $5^{\text {a }}$ classe que desafiam contra as práticas pedagógicas em L2 e contra o professor, exigindo o uso da L1 nas aulas em L2.

\section{Extrato 2: Prof. Milisi (EPC de Wulombe)}

1. Prof. Milisi: Agora por exemplo nesta modalidade que estou usar agora (...), estou a sofrer

2. Investigador: Por que está a sofrer?

3. Prof. Milisi Porque as crianças epa hi:.: todo o momento, quer que a criança aprenda lá dentro usando

4. Investigador: Português

5. Prof. Cirani: Gitonga?

6. Prof. Milisi: Não não, é gitonga

7. Prof. Girisa: Gitonga

8. Investigador: Vagulomba gitonga avo? (eles exigem que se fale gitonga?)

9. Prof. Milisi: Vagulomba gitonga avo (eles exigem que se fale gitonga)

10. Prof. Cirani: I::: hu::: português na sala mesmo na $5^{a}$ é difícil a criança falar em português na aula

11. Prof. Milisi: Estou a lutar mesmo com as crianças. é preciso trabalhar i::

12. Prof. Girisa: A comunicação da criança só é gitonga

13. Prof. Ayenda: É usando só e só português não há-de haver aquela comunicação mesmo que nós desejamos

14. Investigador: Então são duas lutas. he::: são duas guerras, guerra deles que querem gitonga e guerra do prof. que quer português

15. Prof. Cirani: Eles estão mais inclinados no gitonga

16. Prof. Girisa: Egostam crianças

As reflexões dos professores acima ilustram que o ensino em L2 sem a L1 inviabiliza a participação, a comunicação e a aprendizagem dos alunos. Contudo, as orientações emanadas para as classes de pós-transição obrigam que o ensino-aprendizagem seja maioritariamente em L2 e, se necessário, pode-se explorar a L1 a título de meio auxiliar no ensino em L2 para explicar conceitos difíceis em matemática e ciências naturais e avaliar a aula (INDE/MINED, 2003). Estas orientações limitam a atuação dos professores que cumprem cegamente as práticas pedagógicas monolíngues centradas na exposição máxima à L2, fronteiras entre as línguas e o princípio de separação de línguas no ensino (JACOBSON, 1990) e bloqueiam a promoção de espaços de atuação da L1 e da L2 através de pedagogia hetero/transglóssica, como é o caso da translinguagem. Diante deste cenário, alguns professores decidem infringir a orientação de uso das línguas acima exposta, explorando a L1 nas aulas reservadas à L2 através de alternância de códigos como forma de superar as dificuldades impostas pela L2, e outros ainda promovem a orientação monolingue sem o uso da L1, visando preparar os alunos para o exame nacional em L2 no fim da 5ª classe (CHIMBUTANE, 2015). 
Sob o ponto de vista de qualidade do ensino-aprendizagem, nota-se que o ensino em L2 está centrado nos professores, nos métodos passivos (exposição) e nas estratégias de "safetalk" (CHICK, 1996; CHAMBO, 2020). O extrato 3 retrata a reflexão do professor Vinichi que considera a L2 como uma barreira que inviabiliza a qualidade de aprendizagem dos alunos.

\section{Extrato 3: Prof. Vinichi (EPC de Mikhokhweni)}

1. Prof. Vinichi: kusukela tresera nawugondzili hi citshwa se uta laha ka kwarta utekela kuteka (a partir da terceira vens ensinando os alunos em citshwa mas quando transitam para a quarta classe, colocas uma) barreira uveka ((risos)) uku laha (e dizes ao aluno) já é para hitlula laha (saltares aqui), van'wanyani vatlula van'wanyani vatiba kalahaya ka (alguns alunos vão saltar, outros vãose embater naquela) barreira liya (ali), aheee (estás a entender) ((risos)) van'wanyani vatlula vayawa ni madzolo ((risos)) (outros ainda saltarão mas cairão de joelhos) ((risos)) já wawo mhaka ya kona? (estás a ver o problema?). Kwalava ka (Aquela mesma) barreira ya kona nakuhi liya ya cigodho (é um troco) ((risos)) (...) os vídeos já dizem quase tudo. (...) este último, mostra que há problemas de comunicação entre o professor e os alunos. Há uma barreira que é causada pela língua. (...) eheee... então o professor aí falava sozinho e chegava às conclusões sozinho e prontos ((risos))

2. Prof. Andhozani: atiwotisa atlhela atihlamula (você pergunta-se e responde-se)

3. Prof. Vinichi: atlhela atihlamula (e depois responde-se), então orindzela kuyiba simbi basi ((risos)) (fica a espera que o sino toque) (...) atahuma aya (para sair para o) recreio ((risos)) (...) basi atawulawula aku (e retorna à sala de aulas para a dizer aos alunos) até amanhã.

Ainda que num discurso cômico, a reflexão do professor Vinichi situa a L2 como um tronco abismal que, obrigatoriamente, os alunos devem saltar caso queiram progredir academicamente nas classes subsequentes. No entanto, nenhum aluno está habilitado a saltá-lo: uns saltam com sucesso, outros embatem-se contra o tronco e outros saltam-no, mas caem perigosamente com os joelhos. Nestas condições, muitos alunos veem-se, dolorosamente, inibidos de aprender com base na L2 tanto pela baixa proficiência linguística e acadêmica nesta língua como pelas estratégias de ensino usadas pelos professores "você pergunta-se e responde-se", esperando que o sino toque para dispensá-los, dizendo "até amanhã". Esta reflexão mostra que, na realidade, o rendimento pedagógico dos alunos é afetado pela transição e sobretudo, pelas pedagogias monolíngues que se assumem nas classes de póstransição (CUMMINS, 2007). Elas são, em si, um entrave, um tronco abismal que os alunos não conseguem saltar e ainda que o saltem, expõem-se às inúmeras dificuldades para dominar a L2.

\subsection{TRANSLINGUAGEM: “TRADUZIR O PENSAMENTO EM LÍNGUA LOCAL PARA O PORTUGUES E INTERPRETAR ESTE CONHECIMENTO DE PORTUGUÊS PARA A LÍNGUA LOCAL”}

No início deste estudo, os professores referiram que usavam a L1 nas aulas em L2 nas classes de pós-transição, tal como preconiza a translinguagem. Por esta razão, não a consideravam como uma pedagogia inovadora. Contudo, durante a observação das aulas constatou-se que as práticas pedagógicas dos professores exploravam a L2 e a L1 com base na pedagogia monoglóssica (exposição máxima à L2 e separação de línguas), tanto que os alunos apenas usavam a L1 sob elicitação do/a professor/a diferentemente do uso das línguas como um único repertório linguístico (GARCÍA, 2009). O extrato (4) elucida a visão exposta pela professora Lambani (EPC de Ruwani) em relação ao que a proposta pedagógica de translinguagem representa para os alunos.

\section{Extrato 4: Prof. Lambani (EPC de Ruwani)}

(...) só indo para os vídeos zvikomba ku acin'wanana cihatla citsaka hi citshwa (constatar-se-á que a/o aluna/o fica mais esperta/o e aberta/o em citshwa), akama wowulawula cilungu co i::: ((gesticula a cabeça cabisbaixa)) (quando você usa o português ela/e fica cabisbaixa), loko uwulawula hi citshwa calulama ((gesticulou a ação de erguer a cabeça)) (mas quando

\footnotetext{
${ }^{2}$ Este termo surge no estudo sobre o discurso em sala de aula observado por Chick (1996) nas escolas negras de Kwazulu, na África de Sul. Chick (1996) constatara que os professores e os alunos recorriam às estratégias passivas de interação na aula caracterizadas pelo coro propositado pelos professores, variação da tonalidade, repetição de respostas, terminação de frases e/ou palavras entre outras, com o objetivo de camuflar a compreensão e o desenvolvimento da aula e, desta forma, salvaguardar a aplicação de possíveis represálias que o regime de apartheid aplicava aos alunos e aos professores no sistema educativo.
} 
falas em citshwa ela/e ergue a cabeça), ciwuya laha ka kunene (e fala abertamente). (...) já hi cilungu basi e::: tawuya (em português só e::: é muito difícil). Utlela nawena utisintira kambe uku "Ah::: ndzokala kuwulawula zvona? Zvomahisa kuyini? Wazviwo? (Chego ao ponto de sentir-me mal e até questionar-me "Ah::: será que não estou a falar corretamente? O que se passa comigo? Estás a ver?). Já, acho que é vantajoso.

O gesto "baixar a cabeça" está relacionado com a reação dos alunos contra as práticas monolíngues em L2, ao passo que "erguer a cabeça” simboliza a predisposição dos alunos para participar nas aulas quando os professores activam as práticas hetero/transglóssicas através da exploração da L1 nas aulas em L2. Na ótica da professora Lambani, as práticas monolíngues desmotivam a participação dos alunos de tal forma que se pode questionar até que ponto o discurso do/a professor/a é relevante nas aulas. Este extrato ressalta a percepção de que os alunos contradizem a transição precoce no ensino bilíngue, opõem-se à política linguística e educacional assimilacionista e homogeneizante através de atitudes que, a olho nu, exigem a exploração pedagógica heteroglóssica nas aulas de pós-transição. As vantagens deste tipo de práticas vão desde a compreensão dos conteúdos, o desenvolvimento de ambas línguas com enfoque para a L2 e do bilinguismo e ainda, habilitar os alunos à L2 e aos conteúdos acadêmicos (BAKER, 2001). A intervenção do professor Azumbani no extrato 5 reafirma que as práticas pedagógicas de translinguagem constroem um ambiente de "scaffolding" nas aulas.

\section{Extrato 5: Prof. Azumbani (EPC de Citimela)}

Agora, quando começamos já com esta liberdade de ter que transmitir nas duas línguas, a criança já se sentia acomodada (...) aliás, a criança do jeito que fazia era transformar o conhecimento que já tem em cicopi o mesmo só e só para português. (...) esta abertura de espaços de traduzir, usar português - copi de forma planificada, claro, então isto vem catapultar de certa maneira o que as crianças dizem ahhh... afinal isto é isto, isto é isto traduzir o pensamento em língua local para o português e interpretar este conhecimento de português para a língua local. Então, isto incentiva também a sua participação porque as crianças ficam murchas por causa da língua. Isso é uma coisa que eu vivi quando dei aquelas aulas em português...

Analisando o extrato acima nota-se que o "scaffolding" surge como consequência da promoção das práticas pedagógicas hetero/transglóssicas a partir das quais os alunos se sentem livres para pensar em ambas línguas, e por conseguinte, motivam-se para participar activamente na aula. A valência da translinguagem como evidência de manifestação da pedagogia de "scaffolding" observa-se quando a concetualização dos conteúdos constrói-se com base na complementaridade entre as línguas como um único recurso pedagógico e quando os alunos têm a oportunidade de "traduzir o pensamento em língua local para o português e interpretar este conhecimento de português para a língua local”. Nesta ótica, alguns professores da avaliação externa consideravam a translinguagem como uma pedagogia transformadora do ensino-aprendizagem. A título de exemplo, o extrato 6 ilustra o posicionamento do professor Vinichi que, após avaliar as aulas transcritas e os respetivos vídeos, concluiu que a translinguagem permitia a participação activa dos alunos na construção do conhecimento.

\section{Extrato 6: Vinichi (EPC de Mikhokhweni)}

De acordo com o texto que eu li na transcrição pude ver de que de facto os alunos participam abertamente e são ativos. $\mathrm{O}$ nível de interação é de facto satisfatório (...) os alunos de facto abrem-se, falam, participam, constroem ideias porque muitas das vezes o que é difícil é tirar um pensamento numa língua em que você não domina, é difícil desenvolver um pensamento. Então é numa língua que tu falas que é fácil manipular a própria língua, escapar-se de algumas coisas. (...) talvez haja uma necessidade de dizer abertamente que "nesta aula aqui vocês estão livre de falar qualquer língua, aqui não há, não tenham problemas" para as crianças sentirem-se livres e participar.

A análise do extrato acima mostra que mais do que a translinguagem como pedagogia de ensino, os alunos têm a L1 como o recurso a partir do qual desenvolvem o conhecimento e a L2 (BAKER, 2001; GARCÍA; WEI, 2014). Uma das evidências é a participação dos alunos nas aulas, que é dinamizada pela liberalização das línguas que, conforme o professor Vinichi, incentiva aos alunos a sentiremse livres para expor as suas ideias e/ou conhecimentos na aula usando a língua que lhes convier. 


\subsection{TRANSLINGUAGEM: CRÍTICAS A PARTIR DA VISÃO MONOGLÓSSICA}

As práticas de translinguagem suscitaram críticas e questionamentos por parte dos professores subdivididas em três categorias: (i) translinguagem e o exame nacional em L2; (ii) impacto negativo do uso da L1 nas aulas em e de L2 e (iii) significado das construções discursivas translíngues. Na ótica dos professores, as práticas de translinguagem inviabilizam a exposição máxima à L2. Assim, a promoção de duas línguas como um único repertório linguístico na sala de aula não "prepararia os alunos" para dominar a L2, os conteúdos acadêmicos e superar o exame nacional conforme revelam as questões patentes no extrato 7, abaixo.

\section{Extrato 7: Prof. Milisi (EPC de Wulombe)}

Usando esta modalidade que estamos a analisar, arranca $3^{\mathrm{a}}$, 4 $4^{\mathrm{a}}$ e $5^{\mathrm{a}}$ está usando gitonga - português, gitonga - português, será que esta criança está na altura de dominar a língua portuguesa até o fim do II ciclo? (...) a mesma criança será possível enfrentar o mesmo exame de monolingue esta criança?

O currículo do ensino primário submete os alunos do ensino monolingue e bilíngue à realização do exame nacional em português no fim da $5^{\mathrm{a}}$ classe. Por esta razão, os professores do ensino bilíngue têm apenas duas classes $\left(4^{\mathrm{a}}\right.$ e $\left.5^{\mathrm{a}}\right)$ para elevar a proficiência linguística e acadêmica dos alunos em L2 e ensiná-los conteúdos academicamente exigentes (ciências e matemática). Diante deste desafio, os professores preferem aplicar a pedagogia monoglóssica (exposição máxima à L2, evitamento da L1 e separação de línguas), visando assegurar o desenvolvimento linguístico e acadêmico dos alunos em L2, preparando-os para aprovar o exame nacional em L2. Neste diapasão, as práticas pedagógicas da translinguagem são tidas como fatores que deformam (JACOBSON, 1990; COOK, 2001) os alunos a não aprender exclusivamente em L2, isto é, se a L1 for liberalizada nas aulas nas classes de póstransição sem a separação de línguas, os alunos não desenvolverão a L2 mas sim a L1. É com base nesta visão de pedagogia monoglóssica que a professora Andhozani prefere usar o método prever-rever (um método de separação de línguas recomendado para as classes de pós-transição (INDE/MINED, 2003)) ao invés das práticas de translinguagem, conforme ilustra o extrato 8.

\section{Extrato 8: Prof. Andhozani (EPC de Mikhokhweni)}

Para mina yoleyo ya (mim, este método) prever-rever yinene hiku loko utinyiketela kwaleniya ka citshwa basi (é ótimo porque se promover cada vez mais o citshwa) ou muita das vezes hiya kwaleniya, kutaku kutlela kwhatsi a n'wanana alemala kwaleniya. Já leyi ya (estar-se-ia a deformar a criança. Já, na minha opinião, considero o método) prever-rever $h i$ mawonela ya mina ndziwayiwona kwhatsi yinene (em minha opinião, como o mais adequado).

No seguimento desta análise, a professora Girani considera que o uso da L1 nas classes antes da transição para além de "deformar" os alunos, "desatualiza" os professores. Diante desta constatação, a professora Girani propõe que as práticas de translinguagem iniciem a partir da $1^{\text {a }}$ classe e não nas classes de pós-transição pois, desta maneira, evitar-se-ia a "deformação e desatualização" de que são vítimas os alunos e os professores nas classes antes da transição segundo aponta o extrato 9.

Extrato 9: Prof. Girani (EPC de Mikhokhweni)

(...) wena mugondzisi wa kona loko wotinyiketela hi ntamu nguvhu seno ka citshwa seno, watlhela utshama (se o próprio professor centrar-se mais na promoção exagerada do citshwa, corre o risco de ficar) deformado. Já loko utana uyivanyana seno ka cilungu seno utachelanyana (se puder roubar um pouco a língua portuguesa e usar razoavelmente), fazer aquela mistura você também como pessoa não fica muito desatualizado. Sim porque a bilíngue loko hingayiwoni kwhatsi (se prestares mais atenção), de $1^{\text {a }}$ até a $3^{\mathrm{a}}$ apesar de que eu ainda não tenho yadeformara nyana kutsongwana phela (deforma de alguma forma).

Analisando criticamente os extratos 8 e 9 observa-se que ambas professoras veem a importância da L1 no ensino-aprendizagem mas numa perspectiva monoglóssica. Enquanto a professora Andhozani prefere o método de prever-rever a favor da L2, a professora Girani propõe o uso da L2 nas classes reservadas à L1. Estas visões procuram, em comum, obstruir o valor pedagógico da L1 tanto nas classes antes da transição como nas classes de pós-transição. 
O questionamento sobre a relação entre as práticas de translinguagem e o exame, levantado pelos professores, foi comentado pela professora Ayenda (extrato 10, abaixo) após analisar e avaliar crítica e objetivamente as evidências do estudo nas sessões de validação externa.

\section{Extrato 10: Prof. Ayenda (EPC de Wulombe)}

Mas do meu lado eu penso que a criança estará habilitada a falar português, afinal de contas nós não estamos para deixar o português de lado. Nós vamos continuar a dar o português mas vamos misturar as duas línguas no sentido de a criança perceber as coisas na sua língua e ao mesmo tempo traduzir para o português. (...) penso que o exame poderá também enfrentar. Talvez o que eu vejo poderia a criança ter algumas dificuldades de interpretar porque ai no exame nem sempre o professor estará sempre para explicar nas duas línguas é onde poderá ter algumas dificuldades mas uma criança bem preparada na $3^{\mathrm{a}}, 4^{\mathrm{a}}$ e $5^{\mathrm{a}}$ classe ou desde a $1^{\mathrm{a}}$ acho que pode enfrentar o exame na língua portuguesa.

A tese da professora Ayenda entende que a translinguagem, por si, irá preparar os alunos durante três classes e melhor ainda se for desde o início das classes iniciais tal que estariam academicamente munidos de competências e habilidades para realizar o exame em L2. Nestes termos, os alunos compreenderiam os conteúdos em ambas línguas ao ponto de realizarem o exame com mais segurança do que os alunos que aprendem com base nas práticas monolingues em L2.

Na sequência da validação externa, os professores contestaram contra as práticas discursivas translíngues nas aulas. Na visão destes professores, as práticas discursivas translíngues não seriam adequadas para a sala de aulas, conforme ilustra o extrato 11.

\section{Extrato 11: Prof. Giwuti (EPC de Mikhokhweni)}

1. Prof. Giwuti: mina kama ndzinga, go gondza a (quando eu lia o) texto andzizvikumangi kwhatsi hiku (não entendia muito bem) ora vinha citshwa ora português, citshwa e português. Agora eu queria saber bem bem bem a maneira de dar aulas é esta de logo na sala de aulas juntarmos as mesmas línguas?

2. Invest.: Sim, é essa aí a ideia principal.

3. Prof. Giwuti: é de usar as duas línguas?

4. Invest.: Trabalharmos para ver se é viável kutirisa timbiri (usar duas línguas) ou mantemos o modelo (...) de usar só e só português (...) os professores que estão a dar $4^{\text {a }}$ classe bilíngue, a orientação é de que tem de se usar apenas o português, kutsongwani citshwa (e um pouco de citshwa)

5. Prof. Giwuti: no caso de não perceber.

A professora Giwuti não concordava com o uso dos discursos translíngues na sala de aulas "Agora eu queria saber bem bem bem a maneira de dar aulas é esta de logo na sala de aulas juntarmos as mesmas línguas?” tal que apesar da confirmação do investigador em (2), a professora discordou "é de usar as duas línguas?" e expôs as circunstâncias em que a L1 é usada nas aulas "no caso de não perceber". O posicionamento do professor Vinichi, no extrato 12, corrobora com o estranhamento da professora Giwuti. Este sugere que as frases sejam enunciadas numa única língua e que haja barreiras e/ou balizas entre as línguas ao nível discursivo.

\section{Extrato 12: Prof. Vinichi (EPC de Mikhokhweni)}

Isto é uma pesquisa, o que eu pude perceber é que os professores precisarão de uma capacitação, porque começava uma frase em português em que não termina uma frase em português depois vai meter uma palavra em copi numa única construção. Começou em português. É um discurso que começa em português mas vai terminar numa outra língua. Não é um discurso completo. Então a sugestão é que quando se começa um enunciado em língua portuguesa que se termine em língua portuguesa. Mas bem é difícil numa interação com os alunos ahhh... Então o que queria dizer é que a mistura sim mas é preciso algumas barreiras. Se começou em citshwa pelo menos terminar em citshwa a frase completa. É sugestão. Colocar umas pequenas balizas só que é difícil numa interação.

A análise dos extratos 11 e 12 revela que os professores recorriam às suas experiências pedagógicas monolíngues em L2 à pedagogia de separação de línguas para avaliar evidências de práticas discursivas translíngues. Os professores propunham que os discursos bilíngues fossem demarcados através de fronteiras de enunciação de uma língua de cada vez, isto é, um enunciado em L2 e/ou 
enunciado em L1 e nunca enunciados translíngues. Entretanto, é com recurso neste género de discurso de sala de aulas que se construía a aprendizagem de ciências naturais.

\section{DISCUSSÃO}

Este estudo analisou as reflexões e/ou posicionamentos dos professores sobre a pedagogia de translinguagem no ensino de ciências naturais referente à $4^{\text {a }}$ classe do programa de ensino bilíngue vigente em Moçambique. Os professores envolvidos neste estudo tinham experiências de práticas pedagógicas monoglóssicas a partir das quais desenvolviam as aulas no ensino bilíngue mas desconheciam as práticas pedagógicas hetero/transglóssicas. Entretanto, os professores não se conformavam com o ensino em L2 nas classes de pós-transição porque os alunos não possuíam a proficiência linguística e académica em L2 que os possibilitasse participar discursivamente na construção da aprendizagem à semelhança das classes antes da transição lecionadas em L1.

As reflexões e/ou posicionamentos dos professores em relação aos resultados e/ou evidências das práticas pedagógicas de translinguagem em comparação com as práticas pedagógicas monoglóssicas são, por um lado, convergentes e, por outro lado, divergentes dentro dos mesmos critérios e padrões de julgamento. Em relação às reflexões e/ou posicionamentos convergentes, $o$ estudo constatou que, em geral, todos os professores que participaram nos ciclos de pesquisa-ação sobre as práticas pedagógicas de translinguagem nas escolas de ação inovadora teceram posicionamentos favoráveis em relação à viabilidade destas para as classes de pós-transição (DEROO; PONZIO, 2019; MENKEN; SÁNCHEZ, 2019; HOLDWAY; HITCHCOCK, 2018). Entretanto, os professores da validação externa (EPC de Mikhokhweni) apresentaram posicionamentos favoráveis mas, ao mesmo tempo, críticos, céticos e receosos relativamente ao valor pedagógico da translinguagem nas classes de pós-transição. Conforme os seus posicionamentos, concordavam com o fluxo de línguas nas classes de pós-transição, no entanto, discordavam que as respetivas práticas pedagógicas fossem baseadas na liberalização e no uso indiscriminado das línguas como repertórios linguísticos na sala de aulas (MWANZA, 2017). Nestes termos, os professores admitiam a possibilidade de se usar a translinguagem desde que obedecesse à pedagogia monoglóssica (princípio de separação de línguas, exposição máxima da L2 sem a L1 e/ou com a compartimentalização das línguas na sala de aulas (p.e. enunciados discursivos)). Em outras palavras, os professores da validação externa valorizavam a L1 como um recurso pedagógico imprescindível para auxiliar o ensino em L2 nas classes de pós-transição, mas não a valorizavam como parte do repertório linguístico a ser promovido paralelamente com a L2 (BARROS et al., 2020). Este posicionamento confirma a visão monoglóssica dos professores da validação externa, que pressupõe que o uso liberalizado da L1 nas aulas em L2 através das práticas de translinguagem concorreria para reduzir o espaço e o tempo reservados para L2, assim como condicionar a

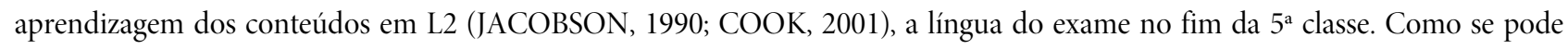
depreender, os professores da validação externa estão mais confiantes em relação à visão pedagógica monoglóssica, ao passo que os professores da validação interna valorizam a visão pedagógica de translinguagem como a que melhor se ajusta aos baixos de proficiência linguística e académica dos alunos em L2 e às exigências acadêmicas das classes de pós-transição (MENKEN; SÁNCHEZ, 2019).

A análise crítica sobre as reflexões e/ou os posicionamentos dos professores constata evidências sólidas de quão as políticas e as ideologias monoglóssicas subjacentes ao ensino bilíngue manifestam-se nas práticas pedagógicas. A avaliação objetiva do papel das línguas nas classes antes e pós-transição elucida que o objetivo do ensino bilíngue é garantir que os alunos aprendam a L2 e em L2 a partir de habilidades da L1. Neste sentido, as visões dos professores ainda que vislumbrem as vantagens pedagógicas das práticas de translinguagem na sala de aulas, ainda manifestam algumas dúvidas sobre quão podem promover a L2, garantir a aprendizagem dos conteúdos e habilitar os alunos para aprovar no exame em L2. Sabe-se que as capacitações que se organizam para os professores lecionarem nas classes de pós-transição continuam a priorizar as ideologias e políticas linguísticas e educacionais monoglóssicas instituídas pelas orientações pedagógicas que assumem a L2 como língua de prestígio em relação à L1. Por esta razão, ainda que os professores constatem dificuldades de ensino-aprendizagem dos alunos em L2, seguem escrupulosamente as orientações pedagógicas monoglóssicas orientadas, outros recorrem a L1 de forma voluntária e a risco próprio (desrespeitando a orientação monoglóssica) para minimizar as dificuldades de aprendizagem associadas à L2 não dominada pelos alunos (CHIMBUTANE, 2015). 
A transição das práticas pedagógicas monoglóssicas para as práticas pedagógicas de translinguagem requer a capacitação e/ou formação pedagógica dos professores, isto é, a negociação entre as práticas anteriores dos professores e as novas práticas hetero/transglóssicas (TICHELOVEN et al., 2019). Os professores que experienciaram as práticas pedagógicas de translinguagem constataram que estas superavam as dificuldades de ensino-aprendizagem dos alunos em L2, e acima de tudo, as práticas pedagógicas monoglóssicas (HOLDWAY; HITCHCOCK, 2018; PROBYN, 2019). Este facto demonstra que a pedagogia de translinguagem é viável para as classes de pós-transição mas, tem de desafiar as ideologias e políticas linguísticas e educacionais subjacentes ao ensino bilíngue (YUVAYAPAN, 2019), enfrentar a visão pedagógica e monoglóssica consolidada entre os professores do ensino bilíngue bem como formar os professores sobre o espaço da pedagogia de translinguagem nos contextos em que o ensino é bi/multilíngue.

\section{CONCLUSÕES}

A pedagogia de translinguagem apresenta-se como uma perspectiva linguística e pedagógica revolucionária no século XXI sobretudo nos contextos multilíngues em que as políticas linguísticas e educacionais valorizam as línguas dominantes (geralmente, L2) em detrimento das línguas minoritárias (L1). Durante séculos o ensino nos contextos multilíngues é desenvolvido com base em pedagogias monoglóssicas que valorizam a L2 com o objetivo de promover a homogeneização linguística. Com o advento da translinguagem, têm surgindo vários estudos promissores que procuram estudar diferentes aspetos relacionados com ensinoaprendizagem de línguas e de conteúdos disciplinares em diferentes subsistemas e currículos tradicionalmente desenvolvidos com base nas pedagogias monoglóssicas.

O propósito deste estudo circunscrevia-se em analisar as reflexões e/ou os posicionamentos dos professores do ensino bilíngue em Moçambique em relação às práticas pedagógicas de translinguagem aplicadas nas classes de pós-transição lecionadas com base nas pedagogias monoglóssicas. A pedagogia de translinguagem rompe a hegemonia da pedagogia monoglóssica que prescreve um ensino baseado na exposição máxima à L2, separação de línguas e evitamento da L1 no ensino-aprendizagem (DEROO; PONZIO, 2019). Esta visão pedagógica não é adequada para os contextos multilíngues muito menos nas situações dos alunos bilíngues emergentes em processo de desenvolvimento do bilinguismo (GARCÍA; WEI, 2014) nos programas de educação bilíngue. Neste sentido, a pedagogia de translinguagem reactiva o valor pedagógico das línguas como repertórios interdependentes que facilitam a construção dos significados no ensino-aprendizagem, resgata o valor pedagógico da L1 e adverte que nenhum ensino pode garantir o desenvolvimento académico dos alunos sem que a L1 e a L2 sejam consideradas como um único repertório linguístico, discursivo e pedagógico no ensino-aprendizagem nos contextos multilíngues ou de minorias linguísticas.

As evidências deste estudo ilustram que as reflexões e/ou posicionamentos dos professores do ensino bilíngue em relação às práticas pedagógicas de translinguagem nas classes de pós-transição tendem a ser influenciados pela pedagogia monoglóssica vigente nas orientações e práticas pedagógicas instituídas pelo MINED/INDE (2003) bem como pela política assimilacionista que se manifesta através da transição de ensino em L1 para L2 na $4^{\mathrm{a}}$ classe e do prestígio pedagógico reservado à L2. Por estas razões, ainda que as práticas de translinguagem sejam pedagogicamente flexíveis e funcionais, os professores do ensino bilíngue envolvidos neste estudo as encaram com algum ceticismo sobretudo quando constatam que estas anulam a hegemonia pedagógica da L2 através da visualização e do uso L1 nas classes de pós-transição reservadas ao ensino em L2. Este ceticismo tende a tornar-se mais acentuado quando os professores constatam que os espaços da L2, uma língua não dominada pelos alunos, são partilhados entre esta e a L1. Contudo, o ceticismo dos professores tende a amainar ligeiramente quando estes constatam evidências que comprovam que as práticas pedagógicas de translinguagem garantem a aprendizagem progressiva e qualitativamente da L2 e dos conteúdos acadêmicos pelos alunos nas classes de pós-transição.

Em jeito de conclusão, este estudo ressalva que, pese embora a pedagogia de translinguagem seja pedagogicamente dinâmica, flexível e adequada para o ensino das classes pós-transição em Moçambique, as reflexões e/ou os posicionamentos dos professores tendem a encará-la numa perspectiva monoglóssica. A mudança desta perspectiva só é possível se os professores observarem as evidências de qualidade da aprendizagem da L2 e dos conteúdos como impacto de uso das práticas pedagógicas translingues nas aulas. 


\section{REFERÊNCIAS}

BAKER, C. Foundations of bilingual education and bilingualism. $3^{\text {rd }}$ edition. Clevedon: Multilingual Matters, 2001.

BARROS, S. et al. Challenging monolingual ways of looking at multilingualism: insights for curriculum development in teacher preparation. Journal of Language, Identity and Education, v. 20, n. 4, p. 239-254, 2020. Disponível em: https://www.tandfonline.com/doi/abs/10.1080/15348458.2020.1753196?.journalCode=hlie20. Acesso em: 26 jan. 2022.

CANAGARAJAH, S. Translanguaging in the classroom: emerging issues for research and pedagogy. Applied Linguistics Review, v. 2, n. 2011, p.1-28, 2011. Disponível em: https://www.degruyter.com/document/doi/10.1515/9783110239331.1/html. Acesso em: 29 jan. 2022.

CHAMBO, G. Desafios discursivos em Português como meio de instrução nas aulas de Ciências Naturais em Moçambique. Calidoscópio, $\quad$ v. $\quad 18, \quad$ n. $\quad 3, \quad$ p. $\quad 547-569, \quad 2020 . \quad$ Disponível em: http://revistas.unisinos.br/index.php/calidoscopio/article/view/cld.2020.183.04/pdf. Acesso em: 21 jan. 2022.

CHAMBO, G. Pedagogia de pressão e insistência linguística em L2, meio de instrução: o silêncio, sussurro e a voz baixa dos alunos de educação bilingue em Moçambique. In: RAMALLO, F. (ed.). Documentos de traballo en ciencias de linguaxe (DTCL). Vigo: GRADES, 2016. p. 71-126.

CHARAMBA, E. Translanguaging in a multilingual class: a study of the relation between students' languages and epistemological access in science. International Journal of Science Education. v. 42, n. 8, p. 1-20, 2020 . Disponível em: https://www.tandfonline.com/doi/abs/10.1080/09500693.2020.1783019?.journalCode=tsed20. Acesso em: 26 jan. 2022.

CHICK, K. Safe-talk: collusion in apartheid education. In: COLEMAN, Hywel. (ed.). Society and the language classroom. New York: Cambridge University Press, 1996. p. 21-39.

CHIMBUTANE, F. O uso da L1 dos alunos como recurso no processo de ensino e aprendizagem de/em Português/L2: o contexto de Ensino Bilingue em Moçambique. Revista Científica da Universidade Eduardo Mondlane, v. 1, n. 1, p. 7-23, 2015. Disponível em: http://www.revistacientifica.uem.mz/revista/index.php/lcs/article/view/38/38. Acesso em: 26 jan. 2022.

COOK, V. Using the first language in the classroom. The Canadian Modern Language Review, v. 53, n. 3, p. 403-423, 2001.

CREESE, A.; BLACKLEDGE, A. Translanguaging in the bilingual classroom: a pedagogy for learning and teaching? Modern Languages Journal, v. 94, n. 1, p. 103-115, 2010. Disponível em: https://onlinelibrary.wiley.com/doi/abs/10.1111/j.15404781.2009.00986.x. Acesso: 29 jan. 2022.

CUMMINS, J. Rethinking monolingual instructional strategies in multilingual classrooms. Canadian Journal of Applied Linguistics/ Revue Canadienne de Linguistique Applique, v. 10, n. 2, p. 221-240, 2007.

DEROO, M.; PONZIO, C. Confronting ideologies: a discourse analysis of in-service teachers' translanguaging stance through an ecological lens. Bilingual Journal Research, v. 42, i. 2, p. 214-231, 2019. Disponível em: https://www.tandfonline.com/doi/abs/10.1080/15235882.2019.1589604?journalCode=ubrj20. Acesso em: 26 jan. 2022.

FLORES, N.; BEARDSMORE, H. B. Programs and structures in bilingual and multilingual education. In: WRIGHT, W.; BOUN, S.; GARCÍA, O. (ed.). Handbook of bilingual and multilingual education. Malden: Wiley-Blackwell, 2015. p. 205-222. 
GARCÍA, O.; WEI, L. Translanguaging: language, bilingualism and education. New York: Palgrave Macmillan. 2014.

GARCÍA, O. Bilingual education in the $21^{\text {st }}$ century: a global perspective. Oxford: Wiley/Blackwell. 2009.

GIBBONS, P. Scaffolding language, scaffolding learning: teaching English language learners in the mainstream classroom, $2^{\text {nd }}$ ed. Portsmouth: Heinemann, 2015.

GRENNER, C.; JÖNSSON, N. H. Teachers' perceptions of the use of translanguaging within English education in grades 4 - 6. 2020. Project. Kultur-Sprâk-Medier, Malmö Universitet. 2020.

HEUGH, K. Theory and practice - language education models in Africa: research, design, decision-making and outcomes. OUANE, A.; GLANZ, C. (ed.). Optimising learning, education and publishing in Africa: the language factor. A review and analysis of theory and practice in mother-tongue and bilingual education in sub-Saharan Africa. UIL/ADEA, 2011. p. 105-155.

HOLDWAY, J.; HITCHCOCK, C. Exploring ideological becoming in professional development for teachers of multilingual learners: perspectives on translanguaging in the classroom. Teaching and Teacher Education. v. 75, p. 60-70, 2018. Disponível em: https://www.learntechlib.org/p/202738/. Acesso em: 26 jan. 2022.

INDE/MINED. Programa de ensino básico - I Ciclo (1ª e 2a Classes). Maputo: INDE/MINED, 2003.

JACOBSON, R.; FALTIS, C. Allocating two languages as a key feature of a bilingual methodology. In: JACOBSON, R.; FALTIS, C. (ed.). Language distribution issues in bilingual schooling. Bristol: Multilingual Matters, 1990. p. 3-17.

JICK, T. Mixing qualitative and qualitative methods: triangulation in action. Administrative Science Quarterly, v. 24, n. 4, p. 602-611, 1979.

MAKALELA, L. Breaking African language boundaries: student teachers' reflections on translanguaging practices. Language Matters, v. 46, n. 2, p. 275-292, 2015. Disponível em: https://www.tandfonline.com/doi/abs/10.1080/10228195.2014.986664. Acesso em: 26 jan. 2022.

MASHINJA, B.; MWANZA, D. The efficacy of translanguaging as pedagogical practice in selected Namibian multilingual primary classrooms. Multilingual Margins. v. 7, n. 3 , p. 49-68. 2020 . Disponível em: https://multimargins.ac.za/index.php/mm/article/view/208. Acesso em: 26 jan. 2022.

MAZRUI, A. The english language in African education: dependency and decolonization. In: TOLLEFSON, J. (ed). Language policies in education: critical issues. London: Lawrence Erlbaum Associates, 2002. p. 267-283.

MCNIFF, J.; WHITEHEAD, J. You and your action research project. $3^{\text {rd }}$ ed. London: Routledge, 2010.

MENKEN, K.; SÁNCHEZ, M. T. Translanguaging in English-only schools: from pedagogy to stance in the disruption of monolingual policies and practices. Tesol Quarterly, v. 0, n. 0, p. 1-27. 2019. Disponível em: https://onlinelibrary.wiley.com/doi/abs/10.1002/tesq.513. Acesso em: 26 jan. 2022.

MINEDH. Estratégia de expansão do ensino bilingue 2020-2029. Maputo: MINEDH, 2019.

MWANZA, D. S. Implications of teachers' attitudes towards unofficial languages on English language teaching in multilingual Zambia. Zambian Journal of Language Studies. v. 1, i. 1, p. 101-124, 2017. Disponível em: https://www.researchgate.net/publication/332230722 Implications of Teachers\%27 Attitudes towards Unofficial languages on English Language Teaching in Multilingual Zambia. Acesso: 29 jan. 2022. 
NYIMBILI, F.; MWANZA, D. S. Translanguaging challenges faced by teachers and learners in first grade multilingual literacy classrooms in Zambia. International Journal on Studies in English Language and Literature. v. 9, i. 3, p. 20-31, 2021. Disponível em: https://www.researchgate.net/publication/350588796 Translanguaging Challenges faced by Teachers and Learners in First Grade Multilingual Literacy Classrooms in Zambia. Acesso: 29 jan. 2022.

OMIDIRE, M. F.; AYOB, S. The utilization of translanguaging for learning and teaching in multilingual primary classrooms. Multilingua. v. 41, n. 1, p. 105-129. 2022. Disponível em: https://www.degruyter.com/document/doi/10.1515/multi-20200072/html. Acesso: 29 jan. 2022.

PROBYN, Margie. Pedagogical translanguaging and the construction of science knowledge in a multilingual South African classroom: challenging monoglossic/post-colonial orthodoxies. Classroom Discourse. v. 10, n. 3-4, p. 216-236, 2019. Disponível em: https://www.tandfonline.com/doi/abs/10.1080/19463014.2019.1628792?.journalCode=rcdi20. Acesso: 29 jan. 2022.

SAHIB, R. et al. West Papuan teachers' perceptions on translanguaging practices in EFL classroom interaction. ELT-Lectura: Studies and Perspectives in English Language Teaching. v. 7, n. 2, p. 73-84. 2020. Disponível em: https://journal.unilak.ac.id/index.php/ELTLectura/article/view/4205. Acesso em: 26 jan. 2022.

STRINGER, E. Action research. $3^{\text {rd }}$ edition. London: Sage Publications, 2007.

TERRA, S. E. Bilingual education in Mozambique: a case-study educational policy, teacher beliefs, and implemented practices. International Journal of Bilingual Education and Bilingualism. v. 24, n. 1, p. 1-15. 2018. Disponível em: https://www.tandfonline.com/doi/abs/10.1080/13670050.2018.1441803. Acesso em: 26 jan. 2022.

TICHELOVEN, A. et al. Translanguaging challenges in multilingual classroom: scholar, teacher, teacher and student perspectives. International Journal of Multilingualism. v. 18, n. 3, p. 491-514. 2019. Disponível em: https://www.tandfonline.com/doi/abs/10.1080/14790718.2019.1686002?.journalCode=rmjm20\#: :text=Overall\%2C\%20seven\%2 0distinct\%20pedagogical\%20challenges, \%3B\%20and\%20(7)\%20Confusion.. Acesso em: 26 jan. 2022.

WANG, D. Translanguaging in Chinese foreign language classrooms students and teachers' attitudes and practices. International Journal of Bilingual Education and Bilingualism. v. 22, i. 2, p. 138-149, 2019. Disponível em: https://www.tandfonline.com/doi/abs/10.1080/13670050.2016.1231773?.journalCode=rbeb20. Acesso em: 26 jan. 2022.

YUVAYAPAN, F. Translanguaging in EFL classrooms: teachers' perceptions and practices. Journal of Languages and Linguistic

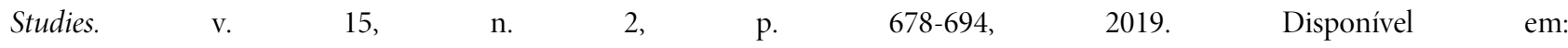
https://www.jlls.org/index.php/jlls/article/view/1312\#: :text=The\%20results\%20showed $\% 20$ that $\% 20 \mathrm{EFL}$, and $\% 20$ parents $\% 20 \mathrm{of} \%$ 20their\%20students. Acesso em: 26 jan. 2022.

\section{(๑) $\circledast \Theta$}

Recebido em 26/04/2021. Aceito em 25/11/2021. 